\title{
Approaches to cheek teeth removal after failed oral extraction in 23 horses
}

\author{
Christof Reichert, Philipp Conze, Anna K. Rötting and Astrid Bienert-Zeit \\ University of Veterinary Medicine Hannover, Foundation, Clinic for Horses, Hannover, Germany
}

\begin{abstract}
Summary: The aim of this study was to describe alternative methods of tooth removal that were used after oral extraction of cheek teeth (CT) had failed or was deemed impossible. For this purpose a review of medical records was performed. A total of 23 CT were removed in 21 horses, of which 8 (34.8\%) were mandibular and 15 (65.2\%) were maxillary. For tooth removal minimal invasive buccotomy was performed in 20 cases, solitary repulsion in 1 case, a combination of repulsion and classical lateral buccotomy in 1 case and a combination of repulsion and minimal invasive buccotomy in 1 case. The removal was successful in all cases. Intra- and postoperative complications occurred in 15/23 cases (65.2\%). Singular complications happened in 8/15 and two or more complications in $7 / 15$ cases. Complications were divided into intraoperative, short- and long-term as well as surgery related and not surgery related complications. The most common reason to use an alternative procedure to oral extraction was a complete fracture of the clinical crown. In one case traumatic crown impingement made oral extraction impossible. All CT were removed successfully with surgery related complications occurring in 12/23 cases (52.2\%). Removal of CT by minimal invasive buccotomy was a useful alternative to repulsion or classical lateral buccotomy in cases of complete fracture or impingement of the crown. If feasible an attempt of oral extraction should first be considered in cases of preexisting partial CT fractures because it is less invasive than any of the alternative approaches. The authors recommend concurrent antimicrobial therapy for horses undergoing minimal invasive buccotomy. Removal of cheek teeth by repulsion or classical buccotomy are indicated in selected cases, and therefor surgeons should also be familiar with these techniques.
\end{abstract}

Keywords: tooth fracture / cheek tooth / horse / minimal invasive buccotomy / repulsion / clinical crown / dentistry

\section{Alternative Methoden zur Entfernung von Backenzähnen nach fehlgeschlagener oraler Extraktion bei 23 Pferden}

Ziel der vorliegenden Arbeit war es, die Indikationen und Ergebnisse alternativer Methoden nach fehlgeschlagener oder unmöglicher oraler Extraktion von Backenzähnen zu beschreiben. Bei 19 Pferden wurde jeweils ein Backenzahn, bei zwei weiteren Pferden jeweils zwei Backenzähne zu unterschiedlichen Zeitpunkten entfernt. Von den 23 entfernten Backenzähnen befanden sich 8 im Unterkiefer und 15 im Oberkiefer. Bei 20 Fällen wurde der entsprechende Zahn mittels minimalinvasiver Bukkotomie entfernt, in einem Fall über eine Repulsion, in einem Fall über eine Kombination aus "klassischer Bukkotomie" und Repulsion und in einem weiteren Fall über eine Kombination aus minimalinvasiver Bukkotomie und Repulsion. In allen Fällen konnte der erkrankte Zahn vollständig entfernt werden. Komplikationen traten bei 15 Fällen (65.2\%) entweder solitär (8/15) oder in Kombination mit anderen Komplikationen (7/15) auf. Sie wurden in intraoperative und kurz- oder langfristige, postoperative Komplikationen unterteilt, sowie in solche mit direktem Bezug zum chirurgischen Eingriff und solche, die unabhängig davon auftraten. Betrachtet man nur Komplikationen mit direktem Bezug zum chirurgischen Eingriff, lag deren Inzidenz bei 52.2\% (12/23). Dabei handelte es sich um das Auftreten orosinusaler Fisteln $(n=6)$, im Zahnfach verbliebene Fragmente ( $n=3)$, Bildung eines Sequesters des Alveolarknochens ( $n=2)$, Blutungen aus der Bukkotomiewunde $(n=2)$, Wundheilungsstörungen im Bereich der Bukkotomiewunde $(n=2)$, eine Eröffnung der A. palatina major $(n=1)$ und die Bildung einer Gewebsnekrose im Bereich der Bukkotomiestelle $(n=1)$. Eine vollständige Fraktur der klinischen Krone war die häufigste Indikation für den Einsatz alternativer Methoden zur oralen Extraktion. In einem Fall war eine orale Extraktion aufgrund einer traumatisch bedingten Impression des Backenzahnes in das Zahnfach nicht möglich. Alle zur Entfernung vorgesehenen Backenzähne wurden erfolgreich entfernt. Die minimalinvasive Bukkotomie stellt bei Kronenfrakturen eine verlässliche Alternative zu der Repulsion oder der klassischen Bukkotomie dar. Aufgrund der geringeren Invasivität sollte, auch in Fällen einer bestehenden Kronenteilfraktur von Backenzähnen, zunächst ein oraler Extraktionsversuch unternommen werden. Wir empfehlen die Anwendung eines Antiinfektivums bei Pferden die einer minimalinvasiven Bukkotomie unterzogen werden. Zudem wurde deutlich, dass sowohl die Repulsion als auch die "klassische" Bukkotomie in Einzelfällen indiziert sind, weshalb der behandelnde Chirurg auch diese Methoden beherrschen sollte.

Schlüsselwörter: Zahnfraktur / Backenzahn / Pferd / minimalinvasive Bukkotomie / Repulsion / Zahnkrone / Zahnheilkunde

Citation: Reichert C., Conze P., Rötting A. K., Bienert-Zeit A. (2014) Approaches to cheek teeth removal after failed oral extraction in 23 cases. Pferdeheilkunde 30, 532-540

Correspondence: Dr. Christof Reichert, Klinik für Pferde, Stiftung Tierärztliche Hochschule Hannover, Germany, E-Mail: christof.reichert@ tiho-hannover.de

\section{Introduction}

Cheek teeth (CT) fractures are one of the main indications for CT extraction in horses (Dixon et al. 2005). There are multiple reasons for the development of CT fractures (Dacre et al. 2007). The overall incidence of CT fracture is reported to be unclear (Dixon et al. 2000a). There are older reports indicating an incidence of equine tooth fractures of $0.71 \%$ (Becker 1945), 8.8\% (Gnädinger et al. 1945) and 3.5\% (Geres 1962). CT fractures have been described to be the reason for $21 \%$ of equine CT extractions (Dixon et al. 2005). CT fractures have been categorized into traumatic and idiopathic (Dixon et al. 2011) whereby traumatic fractures are reported to occur mostly in mandibular and idiopathic fractures in maxillary CT (Dixon et al. 2000a). Fractures can be caused by external, bit-related or iatrogenic trauma. latrogenic traumatic fractures can occur during dental manipulation (Dixon et al. 2000a) and have a reported incidence of $9 \%$ during attempts of standing oral CT extraction (Dixon et al. 
2005). A fracture of the clinical crown limits the possibility of oral extraction and may necessitate alternative approaches for completion of tooth removal. These approaches include a repulsion technique (Mcllwraith and Turner 1987, Turner and Mcllwraith 1989), and a classical (Evans et al. 1982) or a minimal-invasive lateral buccotomy technique (Stoll 2011 , Nowak et al. 2011 ) with or without screw extraction.

Dental repulsion necessitates an apical approach to the tooth (Lane 1997). It is reported to be associated with a higher incidence of postoperative complications (Prichard et al. 1992, Orsini et al. 1992, Lane 1994, Dixon et al. 2000b, Boussauw 2003, Dixon et al. 2005, Bienert 2008) than oral extraction (Bienert 2008). Frequently the tooth to be repulsed is traumatized so that it is often extracted in multiple pieces with the potential for remaining tooth fragments in the alveolus (Dixon et al. 2000b, Dixon et al. 2005). Dixon et al. (2000b) reported continuing purulent discharge from the alveolar surgical site in 6 of 33 cases after mandibular CT repulsion because of sequester formation or development of local mandibular osteomyelitis. The infection resolved following continued antibiotic treatment and curettage over a time period of up to twelve months. In another study (Lane et al. 1994) $35 \%$ of all horses which underwent CT repulsion required a second surgery. Coomer et al. (2011) described standing repulsion to be associated with a lower complication rate compared to repulsion under general anaesthesia.

The classical lateral buccotomy technique was first described by Evans et al. (1982). Lane (1997) compared the repulsion with the lateral buccotomy technique for equine tooth removal. The author found buccotomy to be superior to repulsion because of a lower risk to remove an incorrect tooth or to damage adjacent tissues, a shorter healing time and a lower complication rate. Boussauw (2003) also described buccotomy to be the preferred technique and recommended to avoid repulsion. During buccotomy there is a risk to damage the dorsal and ventral branches of the facial nerve, the buccal venous plexus and the parotic duct. Boussauw (2003) concluded that the lateral buccotomy technique is limited to maxillary and mandibular CT 6 to 9 and in selected cases maxillary CT 10. Dixon et al. (2005) also reported the classical approach to be unsuitable for its use in more caudal CT.

Stoll (2011) described a minimally invasive transbuccal surgery and screw extraction technique as an alternative to trephination and repulsion in cases of crown fractures or other cases in which oral extraction is impossible. Nowak et al. (2011) reported complications associated with minimal invasive buccotomy to occur only in very few cases. They mostly consisted of the development of cheek abscesses, facial nerve paresis, inadvertent penetration of parts of the alveolus and osteomyelitis (Nowak et al. 2011). The aim of this study was to describe the indication and outcome of alternative methods used after oral extraction of CT had failed or was deemed impossible.

\section{Materials and methods}

Medical records from horses admitted to the Clinic from July 2012 to January 2014 were reviewed. Inclusion criteria were a fracture (partial, longitudinal or complete) of the clinical crown of any CT by the time of referral or during an attempt of oral extraction, necessitating an alternative approach for CT removal. One horse was included due to a traumatic impingement of the clinical crown underneath the gingival level.

\section{Alternative approaches - Surgical Procedures}

Minimal invasive buccotomy with and without screw extraction was performed according to the technique described by Stoll (2011). Repulsion was done as described by Turner and Mcllwraith (1989). The applied "classical" lateral buccotomy (horizontal) was described in detail by Tremaine and Schumacher (2011).

\section{Short- and long-term complications}

Short-term complications were defined as complications occurring during the first 14 days after surgery and long-term complications as those occurring later than 14 days after surgery. Long-term complications and outcome were obtained by telephone questionnaire with the owners.

\section{Results}

Horses

21 horses were included in the study. One tooth was extracted in 19 horses and 2 horses had an extraction of two teeth at different time points, resulting in 23 cases of CT removal for this study. The horses' age ranged from 4 to 26 years (1 $1.7 \pm 5.2$, mean \pm SD). Breed distribution was Warmblood $(n=12)$, Pony $(n=3)$, Haflinger $(n=2)$ and one each of the breeds Arabian, Morgan Horse, Thoroughbred and Standardbred.

\section{Diagnosis}

For diagnosis a clinical examination of the oral cavity was done in all cases, oral endoscopy in 17 cases, radiographs were taken in 22 cases, and computed tomography of the skull was performed in 2 cases. In one case in which no radiographs were obtained there was a complete crown fracture of the tooth 310 that occurred during an attempt of oral extraction by the referring veterinarian.

\section{Surgical procedures}

For tooth removal minimal invasive buccotomy was performed in 20 cases, repulsion in 1 case, a combination of repulsion and classical lateral buccotomy in 1 case and a combination of repulsion and minimal invasive buccotomy in 1 case.

\section{Perioperative medication}

In all cases nonsteroidal antiinflammatory drugs (flunixinmeglumine ${ }^{1}, 1.1 \mathrm{mg} / \mathrm{kg}$ bid to sid or meloxicam², $0.6 \mathrm{mg} / \mathrm{kg}$ 
sid,) were administered starting preoperative and continued over a period of 2-12 days after surgery. In all but 3 cases (20/23) antimicrobial drugs were administered, beginning at the day of surgery in $16 / 20$ cases and one day after surgery in $4 / 20$ cases. All of these 20 horses received trimethoprim-sulfonamide (either trimethoprim-sulfadimethoxine ${ }^{3}, 20 \mathrm{mg} / \mathrm{kg}$ bid, or trimethoprim-sulfadiazine $4,30 \mathrm{mg} / \mathrm{kg}$ bid) for 4 to 21 days post surgery. One case additionally received metronidazole 5 $(15 \mathrm{mg} / \mathrm{kg} \mathrm{tid})$ from day 3 to 21 after surgery. Another case received cefquinome ${ }^{6}(1 \mathrm{mg} / \mathrm{kg}$ sid) from day 1 to 5 post surgery and was then switched to a combination of trimethoprimsulfadimethoxine $^{3}(20 \mathrm{mg} / \mathrm{kg}$ bid, day 5 to 11 after surgery) and metronidazole 5 (15 mg/kg tid, day 5 to 10 after surgery).

\section{Chemical restraint and regional anaesthesia}

In all standing procedures horses were placed in equine stokks and sedated. 15/23 (65.2\%) CT were removed standing, $1 / 23(4.4 \%)$ under general anaesthesia and $7 / 23$ (30.4\%) under a combination of both. In 5 of these last 7 cases uncooperative behaviour of the horse made standing extraction impossible and made continuation of the procedure under general anaesthesia at the same day $(n=2)$ or at least one day afterwards $(n=3)$ necessary. In one of these 7 cases surgery was started under general anaesthesia because diagnostic computed tomography was performed in the recumbent horse immediately before surgery. Because of a prolonged anaesthesia time ( $>3 \mathrm{~h}$ ), the procedure was discontinued in this horse and CT removal completed standing two days

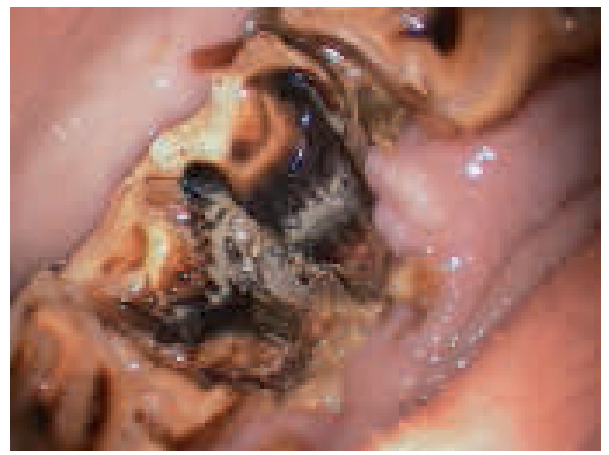

Fig. 1 Oral endoscopic view of an old 109 partial crown fracture on the palatal aspect along infundibula that were altered by caries. Maulhöhlenendoskopische Ansicht der älteren Kronenteilfraktur des 109 auf der Palatinalseite entlang der durch Karies veränderten Infundibula.

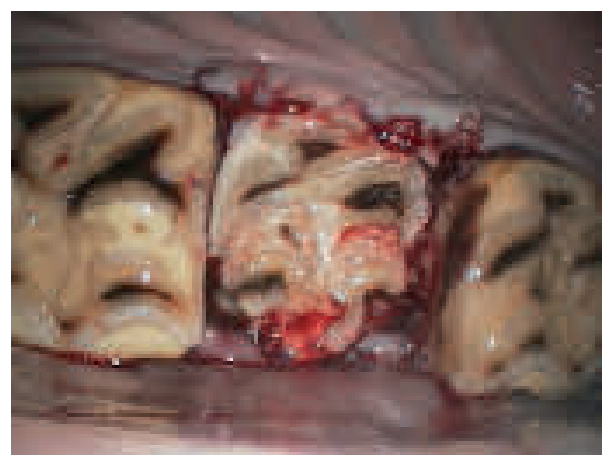

Fig. 2 Oral endoscopic view of a 109 complete crown fracture that occurred during an attempt of oral extraction.

Maulhöhlenendoskopische Ansicht einer vollständigen Kronenfraktur des 109 nach einem oralen Extraktionsversuch. afterwards. In the last of these 7 cases, standing oral extraction failed because of a crown fracture and was followed by an attempt of repulsion in the standing position. This procedure was not successful and the decision was made to perform computed tomography of the skull under general anaesthesia which was followed by removal of the tooth through a classical buccotomy during the same anaesthesia period.

In standing procedures regional anaesthesia of the ipsilateral inferior alveolar or maxillary nerve was performed as described by Tremaine (2007). Additionally a local circumferential block was performed in the gingiva with $10-20 \mathrm{ml}$ of $2 \%$ mepivacainhydrochloride ${ }^{7}$ or $2 \%$ lidocainhydrochloride 8 around the CT to be extracted.

\section{Cheek teeth removal}

A total of 23 CT were removed of which 8/23 (34.8\%) were mandibular and 15/23 (65.2\%) were maxillary. 16/23 $(69.6 \%)$ CT were fractured at the time of referral, $1 / 16(6.2 \%)$ longitudinally, 11/16 (68.8\%) with a partial (Fig. 1) and 4/16 (25\%) with a complete crown fracture. In all cases with partially or longitudinally fractured $C T$, an

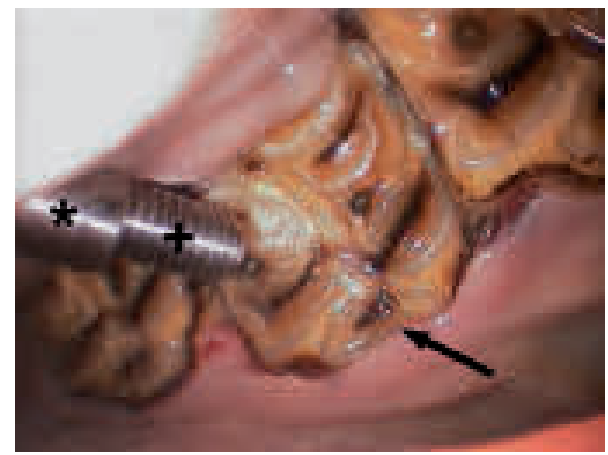

Fig. 3 Oral endoscopic view of a 110 with traumatic impingement. The intact surface of the clinical crown is positioned underneath the gingival level (arrow). For screw extraction via minimal invasive buccotomy the thread hole has been prepared and the screw $(+)$ introduced through the transbuccal protection sheath $\left({ }^{*}\right)$. Maulhöhlenendoskopische Ansicht eines 110 mit traumatisch bedingter Imprimierung einer intakten Zahnkrone unter das Gingivaniveau (Pfeil). Situation während der Schraubextraktion via minimalinvasiver Bukkotomie. Das Gewindeloch ist vorbereitet, die Schraube (+) durch die Bohrschutzhülse (*) eingeführt.

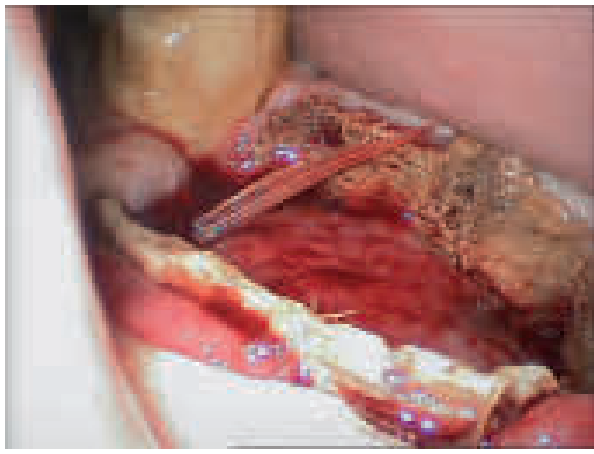

Fig. 5 Oral endoscopic view of an almost circular alveolar sequestrum with granulation tissue centrally presented 10 weeks after surgery (407).

Maulhöhlenendoskopische Ansicht eines nahezu zirkulären Alveolarsequesters mit zentralem Granulationsgewebe etwa 10 Wochen nach dem chirurgischen Eingriff (407). 


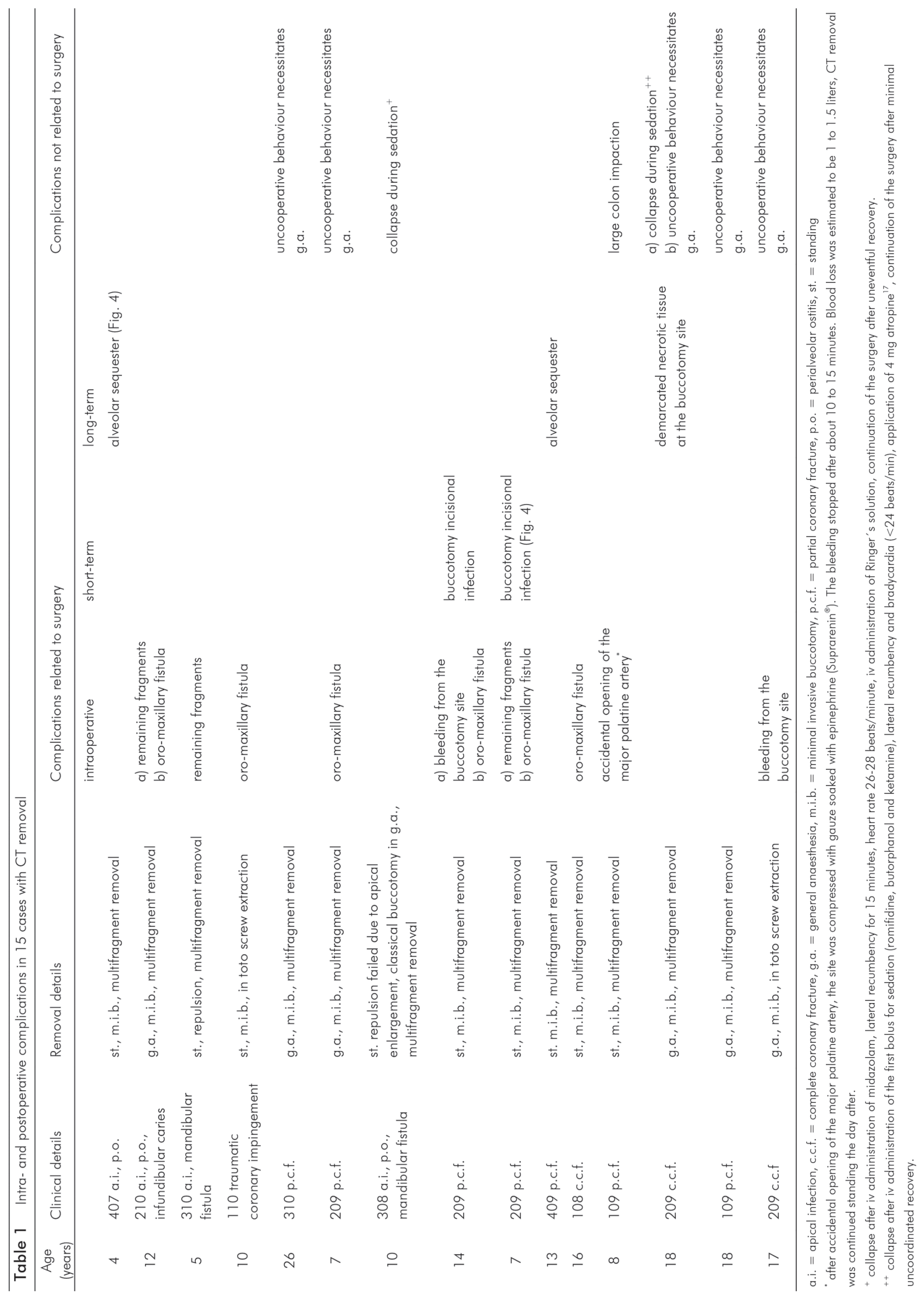


attempt of oral extraction was made. However, in all of these horses a complete crown fracture occurred during manipulation and gripping the tooth with extraction forceps was impossible.

Of the seven cases with an intact clinical crown at the time of referral, 6/7 (85.7\%) fractured while being manipulated for extraction (Fig. 2) and $1 / 7$ (14.3\%) had a traumatic impingement of the tooth underneath the gingival level (Fig. 3) making a classical extraction via an oral approach impossible. Of the six CT which fractured during the attempt of oral extraction, all had an apical infection, 5/6 with additional alveolar periostitis, $3 / 6$ with mandibular fistula formation (308, 308, 310), one with open pulp positions (109, pulp positions $2-5)$, and one with deep caries of both infundibula (210).

Of the 23 teeth, 5 could be removed in one and 18 in multiple pieces. After complete CT removal the alveoli were filled with swabs soaked with a honey containing ointment (Mielosan $\left.{ }^{\circledR}\right)^{9}$ or iodoform (Opraclean $\left.{ }^{\circledR}\right)^{10}$ in 16 cases or with vinyl polysiloxane impression material (VPS Hydro Putty $\left.{ }^{\circledR}\right)^{11}$ in 5 cases. In 2 cases swabs were replaced by vinyl polysiloxane impression material (VPS Hydro Putty $\left.{ }^{\circledR}\right)^{11}$ during hospitalization.

Hospitalization time, complications and telephone questionnaire

Hospitalization time ranged from 0 to 11 days $(2.3 \pm 2.8$, mean $\pm S D)$ before and 1 to 17 days $(4.9 \pm 4.5$, mean $\pm S D)$ after surgery.

Tooth extraction was successful in all cases. Intra- and postoperative complications occurred in $15 / 23$ cases (65.2\%), one complication in $8 / 15$ and two or more complications in $7 / 15$ cases. Details of cases in which complications occurred are shown in table 1. Twelve intraoperative surgery related complications occurred with oro-maxillary fistula formation being the most common $(n=6)$, followed by remaining fragments in the alveolus $(n=3)$, bleeding from the buccotomy site $(n=2)$, and accidental opening of the major palatine artery $(n=1)$. Two short-term surgery related complications (buccotomy incisional infections) and 3 long-term surgery related complications with formation of alveolar sequestrae $(n=2)$ or necrotic tissue at the buccotomy site $(n=1)$ were noted.

Oro-maxillary fistulae were noted in 6/15 (40\%) cases after maxillary CT removal of which two had nasal discharge at the time of referral. Mandibular fistulas were evident in 3 of 8 cases needing mandibular CT removal. These had been evident at the time of presentation and therefore were not regarded as surgery-related complications.

All long-term complications were obtained by telephone questionnaire after hospital discharge. Telephone questionnaire was available for 19/23 cases.

\section{Discussion}

In this case series the most common indication for alternative procedures to oral extraction was a complete fracture of the clinical crown. In all but 3 cases tooth removal could be achieved with a minimal invasive buccotomy technique. In 1 of these 3 cases repulsion was chosen in a five year old horse with a 310 apical infection and fistula formation. This horse had a preexisting fistula over the tooth root that could be used for repulsion, making an additional wound from a buccotomy unnecessary. In another of the 3 cases a combination of repulsion and classical buccotomy was chosen. The 308 had been diagnosed with an apical infection with fistula formation and perialveolar ostitis. The buccotomy was initiated after an unsuccessful attempt to remove the 308 via repulsion. Repulsion probably was unsuccessful because of an enlargement of the tooth root due to chronic periodontal changes that was confirmed with computed tomography. As described by $\mathrm{O}^{\prime}$ Connor (1938) in cases of apical enlargement removal cannot be performed without causing a fracture of the alveolar walls. In these cases a classical lateral buccotomy with apical or lateral alveolar wall resection is indicated (Dixon et al. 2005). In the third case a combination of minimal invasive buccotomy and repulsion was used. The tooth (308) had also been diagnosed with an apical infection with fistula formation and perialveolar ostitis. Minimal invasive buccotomy was the first method chosen, but reached its limits because of the depth of the alveolus in this 5 year old horse. Instruments were too short to reach the tooth fragments to be removed. Therefore the decision was made to remove the remaining fragment by repulsion after an en-largement of the preexisting fistula opening with a trephine.

Boussauw (2003) described 48 procedures of classical lateral buccotomy, with one or more complications occurring in 15/48 cases $(31.3 \%, 12$ wound infections, 7 wound dehiscence, 2 temporary facial paresis, 1 loss of prosthesis, 1 oronasal fistula, 1 temporary hyperaesthesia, 1 second surgery to remove remaining fragments). In that study, horses were not treated with antibiotics, and the author recommended suturing the cheek in three layers avoiding the gingiva and placing a Penrose drain in the wound. In the report by Evans et al. (1982), the authors recommended antibiotic treatment for lateral buccotomy and a similar musculocutaneous suturing technique with absorbable material and nylon. The authors describe the surgery to be a procedure with minimal aftercare and had no complications of facial nerve damage, wound dehiscence, facial scars or oral-maxillary fistulation. $\mathrm{O}^{\prime}$ Neill et al. (2011) reported a surgery related complication rate of $30 \%(34 / 114)$ after CT extraction using classical lateral buccotomy. Complications mainly consisted of wound dehiscence (16/34), followed by facial nerve tauma with temporary $(6 / 34)$ or permanent (3/34) paralysis, myositis (4/34), inadvertent establishment of an oroantral fistula (4/34) and mandibular alveolar infection (1/34).

In the present case series no signs of facial nerve paresis were observed and this could be a potential advantage of the less traumatizing minimal invasive technique. A possible explanation could be the use of the blunt obturator for penetrating the cheek without exception. Nevertheless other authors (Nowak et al. 2011) discussed the potential risk of irreversible facial nerve damage also for the minimal invasive technique but found the risk to be very low. Stoll (2011) reported a transient facial nerve paresis (several hours) in $7 / 22$ cases of minimal invasive transbuccal surgery which were thought to be contributable to local anesthesia of the cheek with lidocaine. 
In this case series, in horses with partial CT fracture an attempt was made to remove the tooth by oral extraction. Dixon et al. (2005) described successful oral extraction in $86 \%$ of cases with preexisting crown fractures. Therefore, alternatives should only be considered in cases with no remnant of the clinical crown protruding over the gingival level, and screw extraction could be a valuable alternative in these cases.

In our case series all of the CT with originally intact clinical crowns showed preexisting alterations with potential weakening of the tooth substance itself (apical infection in 6/6, infundibular caries in $1 / 6$, open pulp positions in $1 / 6$ ) predisposing them to fractures during manipulation (Dixon et al. 2005, Dacre et al. 2007), and all of them did during manipulation.

In our case series oro-maxillary fistulas were present in six cases after CT removal by minimal invasive buccotomy. One of these cases had been diagnosed with a traumatic CT impingement and it can be assumed that the integrity of the alveolus was disturbed before manipulation. After removal the alveolar defect in this horse was extensive, extending over nearly the complete buccal and basal wall of the alveolus. According to the owners it took nearly 6 months to close the fistula with regular flushing and replacement of the implant during that period of time. In another case there was a preexisting apical infection of the 210 with potential weakening or disintegrity of the bottom of the alveolus. The theory of a preexisting disintegrity of the alveolus in these two cases is supported by the fact that nasal discharge was obvious at the time of referral. Nevertheless in the other four cases, fistula formation potentially occurred as a consequence of manipulation. Alveolar damage causing oromaxillary fistula formation can be induced during minimal invasive buccotomy. The most probable reason for fistula formation is an accidental opening of the alveolus while manipulating with chisels to loosen the CT circularly or while drilling for consecutive screw extraction. There is no exact method to measure the depth of the alveolus during surgery. An aid could be measuring the alveolus radiographically and obtaining control radiographs during surgery (Stoll 2011). The authors used a self-made check mark made of tape at the drill to estimate the drilling depth. During drilling the reduction of the distance between the check mark and the basis of the trocar can be used for an estimation of drilling depth into the tooth. Stoll (2011) reported mild mucous nasal discharge after penetration into the maxillary sinus with the drill during a minimal invasive buccotomy technique in 1/22 cases. Nasal discharge ceased after seven days with no additional treatment.

Formation of alveolar sequestra after CT removal has been described independent from the technique used (Prichard et al. 1992, Dixon et al. 2000b, Dixon et al. 2005). Dixon et al. (2005) reported alveolar sequestra in 3/111 (2.7\%) after oral CT extraction with immediate resolution of clinical signs after sequestrectomy. Prichard et al. (1992) described alveolar sequestration as a complication of CT repulsion in 6/36 (17\%) maxillary CT and in 1/25 (4\%) mandibular CT with an overall rate of complications of $47 \%$ in maxillary and $32 \%$ in mandibular CT repulsion. Another study reported the occurrence of sequestra after CT repulsion in 3 of 33 cases (9.1\%) with clinical signs resolving after removal, curettage and fur- ther antibiotic treatment (Dixon et al. 2000b). In our case series a sequestrum formed in $2 / 23$ cases ( $8.7 \%)$, both in the mandibula $(407,409)$, and both after minimal invasive buccotomy with multiple fragments. One horse was referred back to the clinic ten weeks after discharge because of a nonhealing alveolus and bad breath. The sequestrum was removed and wound healing was completed after four weeks according to the referring veterinarian. The sequestrum in the other horse was removed by the referring veterinarian and the alveolus healed without further complications after about 6 weeks. The incidence of sequestrum formation in our study was higher than reported by Prichard et al. (1992) for mandibular CT repulsion, higher than in the report by Dixon et al. (2005) for oral extraction, and comparable to the reported by Dixon et al. (2000b) for repulsion. Loosening of a CT via minimal invasive buccotomy instruments is done under endoscopic guidance or by manual control but an accidental trauma to bony parts of the alveolus during manipulation with chisels cannot be entirely avoided and formation of sequestra could be a consequence.

Bleeding from the buccotomy site occurred in 2 cases. In both cases the 209 was removed. Buccotomy was performed immediately rostral to the facial artery in one horse and in the other the exact localization was not recorded. In one case bleeding was controlled by digital compression and finally stopped without hematoma formation within 5 to 10 minutes. In this case the mucosal part of the buccotomy incision was sutured additionally to the skin. Blood loss was estimated to be 2 liters. In the other case, bleeding stopped with hematoma formation after closure of the wound with skin staples and compression by a head bandage. The facial artery and vein are positioned close to the planned buccotomy site for removal of Triadan 09. They are accompanied by the parotid duct and crossed by the dorsal and ventral buccolabial branch of the facial nerve (Wissdorf et al. 2002a, Wissdorf et al. 2002b). An inadvertent laceration of the facial artery or vein, the parotid duct or the facial nerve is possible during minimal invasive buccotomy (Nowak et al. 2011).

Stoll (2011) reported the occurrence of incisional infection in $1 / 22$ cases of minimal invasive transbuccal surgery. In our series buccotomy incisional infection occurred in 2/23 cases. One case had a formation of a cheek hematoma after bleeding from the buccotomy site. Signs of incisional infection with purulent discharge occurred four days after surgery without reduced behaviour or appetite. Skin staples were removed and the infection site was cleaned daily. The owners were advised to clean the wound until completely healed. A predisposing factor for wound infection in this case could be the presence of a hematoma, since hematoma formation can significantly increase the risk of surgical site infection (O/sen et al. 2008). In the other case the horse developed fever and signs of cellulitis the first day after surgery and purulent discharge from the buccotomy site four days after surgery. This horse had received no antibiotics until the first day after surgery when signs of incisional infection became obvious. It received cefquinome starting the first day after surgery, changing to oral antiinfectives (sulfonamids and metronidazole) on the fifth day after surgery. The infection in this case could be a consequence of the absence of concomitant antiinfective treatment at the time of surgery. Buccotomy sites are predisposed to develop incisional infections because of the inevi- 
table intraoperative contamination and the type and multitude of bacteria that are likely involved. With repeated introduction and removal of instruments through the cheek the tissue is contaminated. Nowak et al. (2011) suggested that the risk of incisional infection during buccotomy can be reduced by the use of a protection sheath. In the present case series a transbuccal protection sheath was used in all cases. Nowak et al. 2011 generally recommended leaving the incision to heal by second intention intra- and extraorally. There is an inevitable risk of contamination during manipulation of the instruments through the cheek (Nowak et al. 2011). In our case series the buccotomy incision was left to heal by second intention intraorally in all but one case and the skin was closed in a single layer with surgical staples or sutures. This potentially could be a predisposing factor for the development of wound infections, particular in the case in which the incision was closed on both sides, mucosa and skin. Obligate anaerobic microorganisms are present as part of the normal flora in the oral cavity of healthy horses (Bailey and Love 1991). Bienert (2002) described that obligate anaerobic microorganisms are the dominating bacterial species in cases of CT diseases in the horse with Fusobacterium spp. and Prevotella spp. being the predominant ones. Therefore the use of metronidazole should be considered especially in cases with clinical signs of surgical site infection.

Demarcated necrotic tissue at the buccotomy site was a longterm complication reported from one owner during telephone questionnaire. The owner had noted an aggravating smell from the buccotomy wound. The referring veterinarian removed the debris and healing was uneventful within days afterwards.

In a study by Dixon et al. (2005), damage to the major palatine artery occurred in 1 of 100 horses having a standing oral extraction. The tooth (108) had a limited palatal clinical crown and the artery was damaged while placing the extractor high up on the palatal aspect. Haemorrhage ceased after digital compression and the tooth was removed the day after. In our case series an accidental opening of the major palatine artery occurred in $1 / 23$ cases $(4.4 \%, 109$ partial crown fracture) during manipulating via the buccotomy approach with a chisel on the palatal aspect of the tooth. The bleeding also ceased without surgical intervention after about 15 minutes of manual compression. We additionally used swabs soaked with adrenalin $^{12}$ in order to achieve a local vasoconstriction. Blood loss was estimated to be about 1 to 1.5 liters. The horse showed signs of mild colic in the evening after the surgery and was diagnosed to have a large colon impaction by transrectal palpation. The impaction resolved after ad-ministration of mineral oil and water via nasogastric intubation. For standing sedation this horse had received romifidine ${ }^{13}$, butorphanol ${ }^{14}$, midazo$\operatorname{lam}^{15}$ and ketamine ${ }^{16}$. One possible explanation for the impaction is the motility reducing effect of $\alpha 2$-agonists on horses small (Zullian et al. 2011 ) and large intestine (König et al. 2008). Another explanation could be the inhibition of motoric neurons of the myenteric plexus by adrenergic neurons (Silbernagl 1991) in cases of adrenergic stimulation by stress resulting in intestinal hypomotility.

The minimally invasive buccotomy technique with screw extraction is not useful in cases with apical enlargement (e.g. in cases of reactive cemental apical deposits or neoplastic enlargement). Apical enlargement results in an altered relationship be- tween the apical and more occlusal part of the alveolus with an abnormally wide apex making oral extraction impossible (O'Connor 1942, Dixon et al. 2000b). In these cases a classical lateral buccotomy with apical or lateral alveolar wall resection can be indicated (Dixon et al. 2005). Alternatively, a minimal invasive buccotomy with removal of tooth remnants in multiple fragments can be performed (Nowak et al. 2011).

In conclusion, removal of CT by minimal invasive buccotomy represented a useful alternative to repulsion or classical lateral buccotomy in in this case series. Nevertheless, because it is less invasive, an attempt of oral extraction should first be made even in cases with preexisting partial crown fractures of CT. The authors recommend concurrent antiinfective therapy for horses undergoing minimal invasive buccotomy. According to our findings combinations of trimethoprime and sulfonamids seem to be appropriate in most cases. Metronidazole should be considered in cases with severe or ongoing surgical site infections because of the high risk of anaerobic infection. Repulsion and classical buccotomy can be indicated in individual cases for removal of fractured CT, and therefore surgeons should also be familiar with these techniques.

\section{Manufacturer's addresses}

1 Flunidol $^{\circledR}$, CP-Pharma GmbH, 31303 Burgdorf, Germany 2 Metacam $^{\circledR}$, Boehringer Ingelheim, Vetmedica $\mathrm{GmbH}$, 55216 Ingelheim, Germany

3 Medistar Arzneimittelvertrieb, 59387 Ascheberg, Germany

4 Synutrim $^{\circledR}$, Vetoquinol GmbH, 88212 Ravensburg, Germany

5 Wald-Apotheke, 23812 Wahlstedt, Germany

6 Cobactan $^{\circledR} 4,5 \%$, MSD Animal Health, Intervet Deutschland $\mathrm{GmbH}, 85716$ Unterschleiß-heim

7 Scandicain ${ }^{\circledR}$, AstraZeneca GmbH, 22876 Wedel, Germany

8 Lidocainhydrochlorid $2 \%{ }^{\circledR}$, bela-pharm GmbH \& Co. KG, 49377 Vechta, Germany

9 Mielosan ${ }^{\circledR}$, CP-Pharma GmbH, Burgdorf, Germany

10 Opraclean ${ }^{\circledR}$, Lohmann \& Rauscher International GmbH und Co. KG, 56579 Rengsdorf, Germany

11 VPS Hydro Putty ${ }^{\circledR}$, Henry Schein Inc., Melville, NY, 1 1747, USA

12 Suprarenin ${ }^{\circledR}$, Sanofi-Aventis Deutschland $\mathrm{GmbH}, 65926$ Frankfurt am Main, Germany

13 Sedivet ${ }^{\circledR}$, Boehringer Ingelheim, Vetmedica GmbH, 55216 Ingelheim, Germany

14 Alvegesic $^{\circledR}$, CP-Pharma GmbH, 31303 Burgdorf, Germany

15 Midazolam B. Braun ${ }^{\circledR}$, B. Braun Melsungen AG, 34209 Melsungen, Germany

16 Ketamin $^{\circledR}$, CP-Pharma GmbH, Burgdorf, Germany

17 Atropinum Sulfuricum 1,0mg Eifelfango ${ }^{\circledR}$, Eifelfango, 53474 Bad Nevenahr-Ahrweiler, Germany

\section{References}

Bailey G. D., Love D. N. (1991) Oral associated bacterial infection in horses: studies on the normal anaerobic flora from the pharyngeal tonsillar surface and its association with lower respiratory tract and paraoral infections. Vet. Microbiol. 26, 367-379

Becker E. (1945) Das Ergebnis von 30000 Zahnuntersuchungen bei Truppenpferden. Z. Veterinärkde. 32, 32-36 
Bienert A. (2002) Digitalradiographische, computertomographische und mikrobiologische Untersuchungen bei Backenzahnerkrankungen des Pferdes. Diss. Med. Vet. Hannover, 163

Bienert A., Bartmann C. P., Feige K. (2008) Vergleich therapeutischer Möglichkeiten zur Behandlung von Backenzahnerkrankungen des Pferdes: Extraktion versus Expulsion. Pferdeheilkunde 23, 419-427

Boussauw B. (2003) Indications and Techniques for Buccotomy. In: BEVA Congress Proceedings, Birmingham, 264-264

Coomer R. P., Fowke G. S., McKane S. (2011) Repulsion of maxillary and mandibular cheek teeth in standing horses. Vet. Surg. 40, 590-595

Dacre I., Kempson S., Dixon P. M. (2007) Equine idiopathic cheek teeth fractures. Part 1: Pathological studies on 35 fractured cheek teeth. Equine Vet. J. 39, 310-318

Dixon P. M., Tremaine W. H., Pickles K., Kuhns L., Hawe C. McCann J., McGorum B. C., Railton D. I., Brammer S. (2000a) Equine dental disease. Part 3: A long-term study of 400 cases: disorders of wear, traumatic damage and idiopathic fractures, tumours and miscellaneous disorders of the cheek teeth. Equine Vet. J. 32, 9-18

Dixon P. M., Tremaine W. H., Pickles K., Kuhns L., Hawe C., McCann J., McGorum B. C., Railton D. I., Brammer S. (2000b) Equine dental disease part 4: A long-term study of 400 cases: apical infections of cheek teeth. Equine Vet. J. 32, 182-194

Dixon P. M., Dacre I., Dacre K., Tremaine W. H., McCann J., Barakzai S. (2005) Standing oral extraction of cheek teeth in 100 horses (1998-2003). Equine Vet. J. 37, 105-112

Dixon P. M., DuTroit N., Dacre I. (2011) Equine dental pathology. In: Equine Dentistry. Easley J., Dixon P.M., Schumacher J. (eds.), Saunders, Elsevier, Edinburgh, 129-148

Evans L. H., Lloyd P. T., LaDow C. S. (1982) Extraction of the equine 4th upper premolar and 1 st and 2 nd upper molars through a lateral buccotomy. In: Proceedings of the 27th Annual Convention of the AAEP, New Orleans, 249-252

Geres V. (1962) Beitrag zur Pathologie und Diagnostik der Zahnerkrankungen der Pferde. Vet. Arhiv. 32, 260-261

Gnädinger F. (1945) Erhebungen über die Häufigkeit von Zahnerkrankungen beim Pferd. Diss. Med. Vet., Hannover, 76-80

Koenig J. B., Martin C. E., Nykamp S. G., Mintchev M. P. (2008) Use of multichannel electrointestinography for noninvasive assessment of myoelectrical activity in the cecum and large colon of horses. Am. J. Vet. Res. 2008 69, 709-715

Lane J. G. (1994) A review of dental disorders of the horse, their treatment and possible fresh approaches to management. Equine Vet. Ed. 1, 13-21

Lane J. G. (1997) Equine dental extraction - Repulsion vs. Buccotomy: Techniques and Results. In: Proceedings of the 5th World Veterinary Dental Congress, Birmingham, 135-138

Mcllwraith C. W., Turner A. S. (1987) Surgery of the gastrointestinal tract. In: Equine Surgery - Advanced Techniques. Mcllwraith C.W., Turner A.S. (eds.) Lea \& Febiger, Malvern, Pennsylvania 1st ed. 260-263
Nowak M., Schulte-Bahrenberg S., Stoll M. (2011) Bukkotomie. In: Lehrbuch der Zahnheilkunde beim Pferd. Vogt C. (Hrsg.) Schattauer, Stuttgart, 1. Auflage, 208-215

O'Connor J. J. (1938) Operations. In: Dollar s Veterinary Surgery, 3rd ed., Alexander Eger, Chicago, 252-257

Olsen M. A., Butler A. M., Willers D. M., Devkota P., Gross G. A., Fraser V. J. (2008) Risk factors for surgical site infection after low transverse cesarean section. Infect. Control. Hosp. Epidemiol. 29, 477-484

O'Neill H. D., Boussauw B., Bladon B. M., Fraser B. S. (2011) Extraction of cheek teeth using a lateral buccotomy approach in 114 horses (1999-2009). Equine Vet. J. 43, 348-353

Orsini P. G., Ross M. W., Hamir A. N. (1992) Levator nasolabialis muscle transposition to prevent an orosinus fistula after tooth extraction in horses. Vet. Surg. 21, 150-156

Prichard M. A., Hackett R. P., Erb H. N. (1992) Long-term outcome of tooth repulsion in horses. A retrospective study of 61 cases. Vet. Surg. 21, 145-149

Silbernagl S. (1991) Dünndarm: Bau und Motilität. In: Taschenatlas der Physiologie. Silbernagl S. and Despopoulos A. (eds.), 4th ed., Thieme Verlag, Stuttgart, 210

Stoll M. (2011) Minimally Invasive Transbuccal Surgery and Screw Extraction. In: AAEP-Focus on dentistry meeting proceedings, Albuquerque, New Mexico, 170-177

Tremaine W. H. (2007) Local analgesic techniques for the equine head. Equine vet. Educ. 19, 495-503

Tremaine W. H., Schumacher J. (2011) Exodontia In: Equine Dentistry. Easley J., Dixon P.M., Schumacher J. (eds.), Saunders, Elsevier, Edinburgh, 319-344

Turner A. S., Mcllwraith C. W. (1989) Repulsion of cheek teeth. In: Techniques in Large Animal Surgery. Turner A.S., Mcllwraith C.W. (eds.) Lea \& Febiger, Philadelphia, 2nd ed. 235-239

Wissdorf H., Otto B., Gerhards H. (2002a) Subkutane Schleimbeutel, klinisch bedeutsame Kopfgefäße und oberflächlich gelegene Lymphknoten. In: Praxisorientierte Anatomie und Propädeutik des Pferdes. Wissdorf H., Gerhards H., Huskamp B., Deegen E. (Hrsg.) Schaper Verlag, Hannover, 89-94

Wissdorf H., Otto B., Huskamp B. (2002b) Nasenhöhle und Nasennebenhöhlen. In: Praxisorientierte Anatomie und Propädeutik des Pferdes. Wissdorf H., Gerhards H., Huskamp B., Deegen E. (Hrsg.) Schaper Verlag, Hannover, 190-201

Zullian C., Menozzi A., Pozzoli C., Poli E., Bertini S. (2011) Effects of 2-adrenergic drugs on small intestinal motility in the horse: an in vitro study. Vet. J. 187, 342-346

\section{Conflict of Interest statement}

None of the authors are subject to any conflicts of interest in regard to the medicals or technical equipments noted in this article. 